\title{
LKPD Stoikiometri Berbasis Inkuiri Terstruktur dengan Tiga Level Representasi untuk Kelas X SMA
}

\section{Stoichiometry Student Worksheet \\ Based on Structured Inquiry with Three Levels of Chemical Representation for $10^{\text {th }}$ Grade Senior High School}

\author{
M L Melini ${ }^{1}$ and M Azhar ${ }^{1 *}$ \\ ${ }^{1}$ Pendidikan Kimia, Universitas Negeri Padang, Jl. Prof. Dr. Hamka, Air Tawar Barat, \\ Padang Utara, Sumatera Barat, Indonesia 25171 \\ *minda@fmipa.unp.ac.id
}

\section{ARTICLE INFO}

Received 16 October 2019

Revised 20 October 2019

Accepted 20 October 2019

\begin{abstract}
This type of study is research and development (R \& D) with 4-D development model. The research was conducted until the validity and practical test of the development. This student worksheet validated by 5 people validators namely 3 chemistry lectures and 2 chemistry teachers from SMAN 1 Linggo Sari Baganti. Practicality questionnaire was filled by 29 students of class XI and 2 chemical teachers of SMAN 1 Linggo Sari Baganti. The result showed that validity test is 0,87 categorized very high. The kappa's moment of practical test by 2 chemstry teacher is 0,78 categorized high. The kappa's moment of 29 students SMAN 1 Linggo Sari Baganti was 0,81 with a high practicality category.
\end{abstract}

\section{KEYWORDS}

Student worksheets, Stoichiometry, Structured inquiry, Three levels chemical representation, 4-D models.

\begin{abstract}
ABSTRAK
Jenis penelitian ini adalah penelitian dan pengembangan ( $R$ \& D) dengan menggunakan model pengembangan 4-D. Penelitian ini dilakukan sampai uji validitas dan praktikalitas dari tahap pengembangan. LKPD divalidasi oleh 5 orang validator yaitu 3 dosen kimia dan 2 guru kimia dari SMAN 1 Linggo Sari Baganti. Angket praktikalitas diisi oleh 29 peserta didik kelas XI dan 2 guru kimia dari SMAN 1 Linggo Sari Baganti. Hasil penelitian menunjukkan uji validitas adalah 0,87 dikategorikan sangat tinggi. Momen kappa uji praktikalitas oleh 2 guru kimia adalah 0,78 dikategorikan tinggi. Momen kappa dari 29 peserta didik SMAN 1 Linggo Sari Baganti adalah 0,81 dengan kategori praktikalitas sangat tinggi.
\end{abstract}

\section{KATA KUNCI}

LKPD, stoikiometri, inkuiri terstruktur, tiga level representasi kimia, model $4-\mathrm{D}$ 


\section{PENDAHULUAN}

Salah satu materi pembelajaran kimia yang dipelajari di kelas X SMA pada semester dua adalah stoikiometri. Stoikiometri merupakan ilmu yang mempelajari jumlah zat yang dikonsumsi dan diproduksi dalam reaksi kimia ${ }^{[1]}$. Stoikiometri memuat materi abstrak dan cukup kompleks untuk dipahami karena memiliki hubungan materi satu dengan materi yang lain yang cukup erat serta memiliki hitung-hitungan sehingga sulit dipahami oleh peserta didik ${ }^{[2]}$.

Dalam mempelajari materi stoikiometri ini peserta didik sering kesulitan dalam memahami persamaan reaksi, konsep mol, perhitungan yang terdapat pada reaksi kimia serta menginterpresentasikan permasalahan verbal menjadi persamaan yang sistematis ${ }^{[3]}$. Peserta didik lebih cendrung menghafal dalam mengatasi kesulitan yang dihadapi pada materi abstrak sehingga menyebabkan peserta didik tidak paham konsep ${ }^{[2]}$. Dalam mempelajari suatu ilmu yang bersifat abstrak terutama kimia hendaknya memperhatikan tiga level representasi kimia.

Ketiga level representasi kimia tersebut adalah representasi makroskopik, representasi submiroskopik dan representasi simbolik. Kemampuan dalam menghubungkan ketiga level representasi kimia ini dapat menentukan tingkat kepahaman seseorang terhadap materi kimia ${ }^{[4]}$. Hal ini karena fenomena kimia yang diamati secara makroskopik merupakan dasar dari kimia, fenomena ini dilandasi dengan penjelasan level submikroskopik dan simbolik sehingga kemampuan peserta didik dalam memahami dan menghubungkan ketiga level representasi menjadi sangat penting untuk menjelaskan fenomena makroskopik ${ }^{[5]}$.

Pemahaman stoikiometri dengan tiga level representasi kimia dapat diaplikasikan ke dalam bahan ajar. Lembar kerja peserta didik (LKPD) adalah salah satu jenis bahan ajar cetak yang dapat digunakan dalam pembelajaran. LKPD ini berupa latihan-latihan yang harus diselesaikan peserta didik $^{[6]}$. Peserta didik akan terdorong aktif dalam menemukan dan mengembangkan konsep serta keterampilan apabila menggunakan LKPD pada pembelajaran $^{[7]}$.

LKPD yang memuat pendekatan pembelajaran yang sesuai sangat diperlukan agar tujuan pembelajaran tercapai. Dalam menjelaskan materi pada kurikulum 2013 digunakan pendekatan saintifik. Pendekatan saintifik terdiri dari tahap observasi, perumusan pertanyaan dan hipotesis, mengelompokkan data, menganalisis data dan menyimpulkan serta mengkomunikasikannya ${ }^{[8]}$. Inkuiri merupakan salah satu model pembelajaran yang memiliki kesesuaian dengan pendekatan saintifik. Pada Inkuiri, informasi diperoleh melalui pengamatan agar dapat memecahkan permasalahan seacara sistematis dan berpikir kritis ${ }^{[9]}$.

Inkuiri terstruktur adalah salah satu jenis model pembelajaran inkuiri yang efektif diterapkan pada proses sains ${ }^{[10]}$. Pada inkuiri terstruktur, peserta didik diberikan pertanyaan, permasalahan, dan prosedur, kemudian peserta didik dituntut menemukan hasil dan kesimpulan utuk memecahkan permasalahan tersebut ${ }^{[11]}$. Peserta didik melakukan penyelidikan secara langsung untuk mengembangkan kemampuan penyelidikan dasarnya seperti melakukan pengamatan, membuat hipotesis, mengumpulkan dan mengolah data, menarik kesimpulan dan menemukan solusi ${ }^{[2]}$. Pembelajaran menggunakan inkuiri terstruktur membuat peserta didik lebih memahami konsep dan mengingat informasi dalam waktu yang lama, serta mengarahkan peserta didik pada pengetahuan yang berkelanjutan ${ }^{[13]}$. Selain itu, dapat menumbuhkan keinginan belajar dan meningkatkan aktivitas peserta didik ${ }^{[14]}$.

Berdasarkan masalah di atas, maka pengembangan LKPD berbasis inkuiri terstruktur dengan tiga level representasi perlu dilakukan. LKPD stoikiometri berbasis inkuiri terstruktur dengan tiga level representasi untuk kelas X SMA di uji validitas dan praktikalitasnya.

\section{METODE}

Jenis penelitian ini adalah R \& D. Penelitian ini merupakan metoda yang digunakan untuk membuat produk atau mengembangkan produk kemudian produk tersebut diuji ${ }^{15]}$. Model 4-D adalah model pengembangan LKPD yang digunakan yang terdiri atas tahap pendefenisian (define), perancangan (design), pengembangan (develop) dan penyebaran (disseminate). Karena keterbatasan waktu dan biaya maka pengembangan LKPD ini dilakukan sampai tahap develop yaitu uji validitas dan praktikalitas. Responden penelitian ini adalah 3 dosen kimia FMIPA, 2 guru kimia dan 29 orang peserta didik XI IPA 3 SMAN 1 Linggo Sari Baganti. Untuk menganalisis data digunakan formula kappa cohen.

$$
\begin{aligned}
& \text { momenkappa }(\kappa)=\frac{\rho_{0}-\rho_{\varepsilon}}{1-\rho_{\varepsilon}} \\
\mathrm{K}= & \text { momen kappa } \\
\rho_{\mathrm{O}}= & \text { Proporsi yang terealisasi } \\
\rho_{\varepsilon}= & \text { Proporsi yang tidak terealisasi }
\end{aligned}
$$

Tabel 1. Kategori Keputusan berdasarkan momen kappa $^{[16]}$

\begin{tabular}{c|c} 
Interval & Kategori \\
\hline $0,81-1,00$ & Sangat tinggi \\
\hline $0,61-0,80$ & Tinggi \\
\hline $0,41-0,60$ & Sedang \\
\hline $0,21-0,40$ & Rendah \\
\hline $0,01-0,20$ & Sangat rendah \\
\hline$<0,00$ & Tidak valid
\end{tabular}


Instrumen yang digunakan yaitu angket validasi dan praktikalitas. Angket validasi ini ditujukan kepada dosen kimia FMIPA UNP dan guru kimia. LKPD yang telah divalidasi oleh validator direvisi sesuai saran validator kemudian diserahkan kembali kepada validator untuk didiskusikan kembali. Apabila LKPD dinyatakan valid maka dapat dilanjutkan dengan uji praktikalitas. Angket praktikalitas digunakan untuk mengetahui tingkat kepraktisan LKPD. Angket praktikalitas ini diisi oleh guru kimia dan peserta didik.

\section{HASIL DAN DISKUSI}

\subsection{Tahap Define}

\subsubsection{Analisis ujung depan}

Pada analisis ini dilakukan wawancara dengan guru kimia untuk mengetahui permasalahan yang terjadi dalam pembelajaran. Dari data wawancara dengan guru SMAN 1 Linggo Sari Baganti dan SMA Pembangunan Laboratorium UNP diperoleh hasil berikut: (1) sebagian peserta didik masih sulit memahami materi stoikiometri. Disebabkan karena materi stoikiometri memuat materi abstrak dan cukup kompleks untuk dipahami karena memiliki hubungan materi satu dengan materi yang lain yang cukup erat serta memiliki hitung-hitungan sehingga sulit dipahami oleh peserta $\operatorname{didik}^{[2]}$; (2) Peserta didik menggunakan bahan ajar berupa buku paket,modul dan LKPD. Materi yang disajikan pada modul lebih sering mengambang dan LKPD yang digunakan berisi soal-soal latihan yang lebih bersifat melatih peserta didik dalam menjawab soal saja dan belum menuntun peserta didik menemukan konsep sendiri; (3) bahan ajar yang digunakan belum memuat tahapan-tahapan model pembelajaran yang digunakan guru dan belum memuat tiga level representasi kimia.

\subsubsection{Analisis peserta didik.}

Hasil olahan angket observasi yang diisi oleh peserta didik SMA Pembangunan Laboratoriun UNP dan SMAN 1 Linggo Sari Baganti diperoleh hasil sebagai berikut: (1) sebanyak $53 \%$ peserta didik SMA Pembangunan Laboratorium UNP dan 63\% SMAN 1 Linggo Sari Baganti mengalami kesulitan memahami materi stoikiometri; (2) Bahan ajar yang mudah dipahami, menarik, bergambar dan berwarna lebih disukai peserta didik.

\subsubsection{Analisis tugas}

Berdasarkan permendikbud nomor 37 tahun 2018 dilakukan analisis kompetensi dasar (KD) yakni sebagai berikut: 3.10. Menerapakan hukumhukum dasar kimia, konsep massa molekul relatif, persamaan reaksi, konsep mol, dan kadar zat untuk menyelesaikan perhitungan kimia ${ }^{[17]}$. Berdasarkan kompetensi dasar dirumuskan indikator pencapaian kompetensi untuk melihat ketercapaiannya, yaitu: 1) Menjelaskan pengertian mol; 2) Menentukan massa molar suatu unsur dan senyawa yang diketahui Ar/Mrnya; 3) Menghitung nilai volume molar gas berdasarkan nillai mol yang diketahui;
4) Menentukan rumus empiris suatu senyawa berdasarkan data eksperimen; 5) Menentukan rumus molekul jika diketahui rumus empirisnya; 6) Menuliskan persamaan reaksi; 7) Menyetarakan persamaan reaksi; 8) Menerapkan koefisien reaksi untuk menentukan pereaksi pembatas.

\subsubsection{Analisis konsep}

Pada analisis ini dilakukan identifikasi terhadap konsep-konsep yang akan diajarkan. Pada materi stoikiometri konsep yang dibahas adalah mol, koefisien reaksi, jumlah partikel, tetapan avogadro, massa molar, volume molar gas, persamaan reaksi, reaktan, produk, reaktan berlebih, reaktan pembatas, rumus kimia, rumus empiris,rumus struktur, rumus molekul, rumus senyawa ion, ion negatif, ion positif, molekul, atom-atom dan subkrib. Konsepkonsep tersebut dianalisis berdasarkan buku kimia perguruan tinggi dan buku kimia SMA.

\subsubsection{Analisis tujuan pembelajaran}

Perumusan tujuan pembelajaran berdasarkan penurunan KD menjadi IPK, kemudian tujuan pembelajaran dirumuskan dari IPK. Pada materi stoikiometri tujuan pembelajarannya adalah peserta didik mampu menggali informasi, melakukan penyelidikan dan mengolah informasi melalui model pembelajaran inkuiri terstruktur sehingga peserta didik aktif dalam proses pembelajaran, memiliki sifat keingintahuan, ketelitian dalam mengamati dan bertanggung jawab dalam berpendapat, memberikan jawaban pertanyaan, memberikan saran, mengkritik, serta peserta didik mampu menjelaskan pengertian mol, menentukan massa molar, menghitung volume molar gas, menentukan rumus kimia, menuliskan persamaan reaksi dan menyetarakan persamaan reaksi, serta menerapkan koefisien reaksi untuk menentukan pereaksi pembatas.

\subsection{Tahap Design}

Tahap ini bertujuan untuk mendesain LKPD stoikiometri berbasis inkuiri terstruktur dengan tiga level representasi kimia. Komponen-komponen penyusunan LKPD yang dirancang yaitu: cover, petuntuk penggunaan, kompetensi yang akan dicapai, peta konsep, langkah kerja, tugas, dan evaluasi. Cover dapat dilihat pada Gambar 1 dan langkah kerja bisa dilihat pada Gambar 2. 


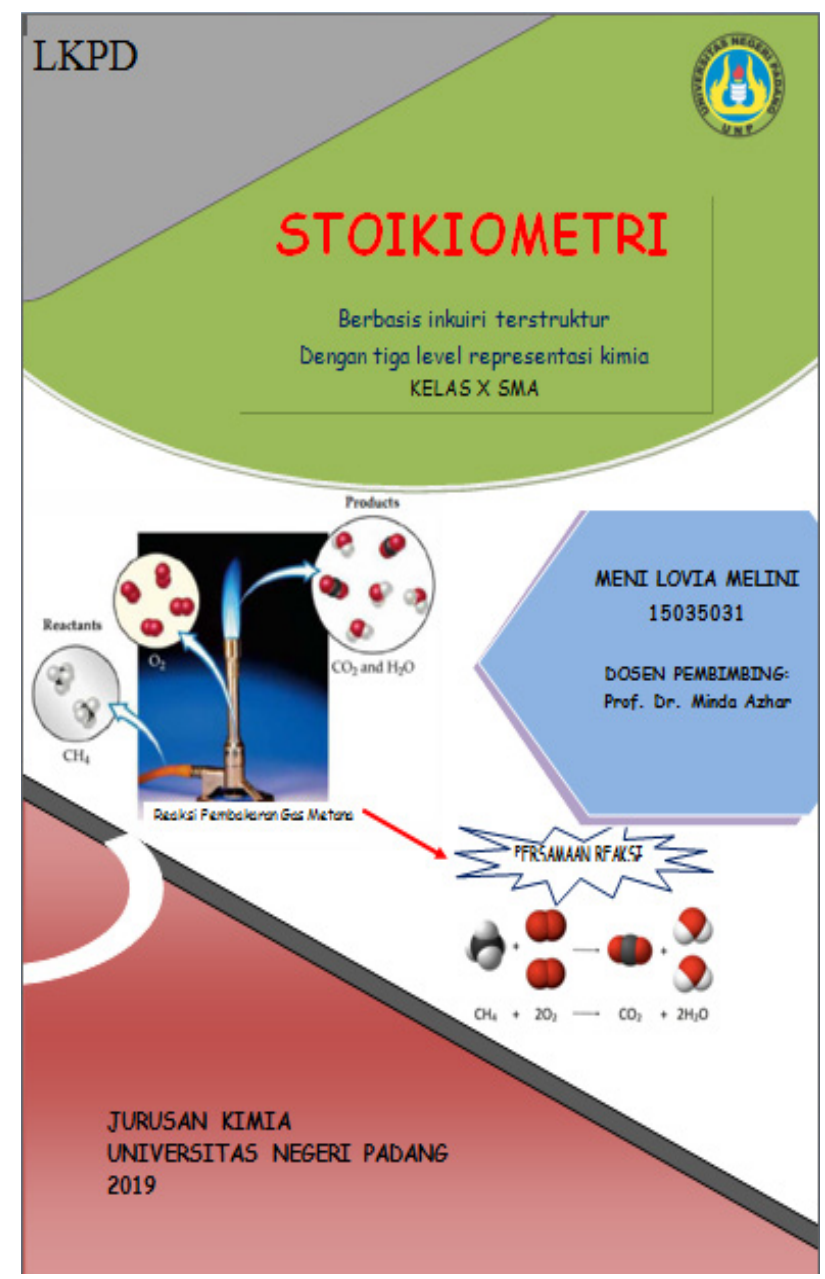

Gambar 1. Cover

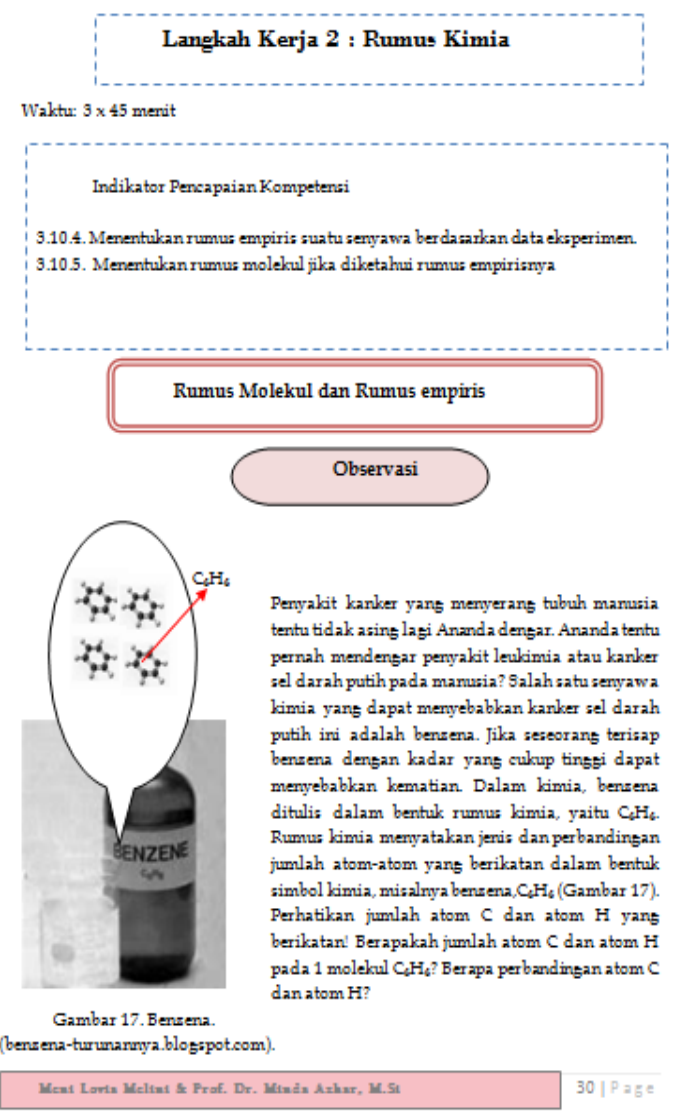

Gambar 2. Langkah kerja.

\subsection{Tahap develop}

\subsubsection{Uji validasi}

Validitas merupakan penilaian terhadap rancangan suatu produk. Apabila instrument yang digunakan dapat mengukur produk yang diukur maka produk tersebut dikatakan valid ${ }^{18]}$. Validitas LKPD ini terdiri atas beberapa aspek yaitu: kelayakan isi, kelayakan kontruksi, komponen kebahasaan, dan komponen kegrafisan. Validitas diuji minimal oleh 3 orang ahli $^{[19]}$. Pada penelitian dilakukan oleh 5 validator yaitu 3 dosen kimia FMIPA UNP dan 2 guru kimia SMAN 1 Linggo Sari Baganti. Untuk menilai validitas LKPD digunakan lembar validasi yang terdiri dari 2. Perolehan hasil dapat dilihat pada Gambar 3.

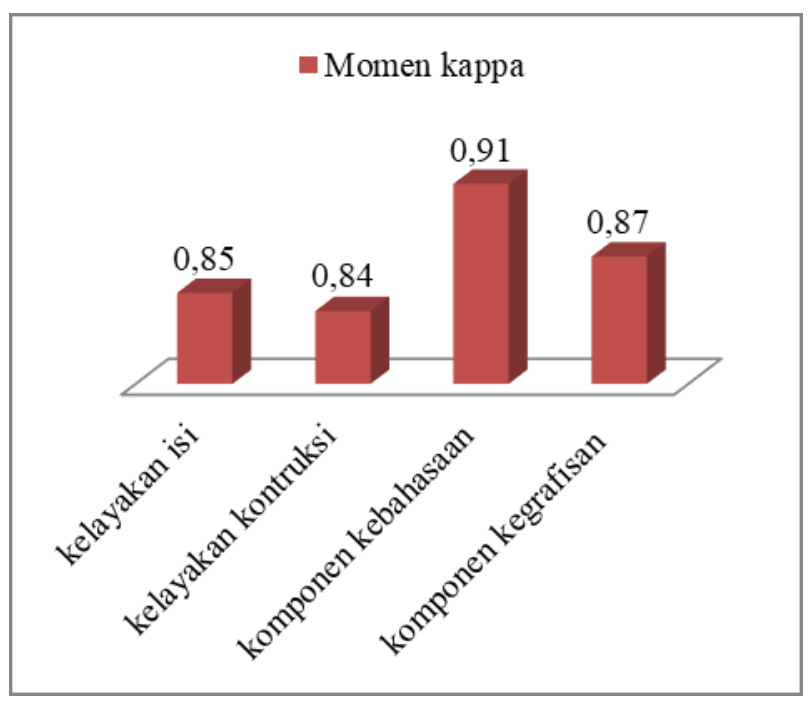

Gambar 3. Hasil analisis data validitas oleh validator.

Momen kappa rata-rata dari analisis data validitas komponen kelayakan isi adalah 0,85 dikategorikan sangat tinggi. Membuktikan LKPD stoikiometri berbasis inkuiri terstruktur dengan tiga level representasi yang dikembangkan sudah valid dan sesuai dengan kompetensi dasar, indikator pencapaian kompetensi dan tujuan pembelajaran yang akan dicapai. Selain itu, pertanyaan yang terdapat pada LKPD tidak memiliki makna ambigu dan membantu peserta didik menemukan konsep stoikiometri. Kalimat-kalimat dalam LKPD telah menekankan pada tiga level representasi untuk memudahkan peserta didik dalam menguasai materi stoikiometri. LKPD yang dikembangkan menyediakan latihan yang merupakan aplikasi langsung dari konsep yang dipelajari. LKPD dinyatakan memiliki kelayakan isi apabila LKPD yang dikembangkan memuat kompetensi sesuai dengan kurikulum 2013 $3^{[6]}$.

Kelayakan konstruksi LKPD stoikiometri berbasis inkuiri terstruktur dengan tiga level representasi memiliki momen kappa rata-rata 0,84 dikategorikan sangat tinggi. Membuktikan LKPD stoikiometri yang disusun sudah sistematik mengikuti komponen-komponen penyusunan LKPD. Tujuan pembelajaran yang dicapai tergambar 
pada pertanyaan-pertanyaan yang diajukan dalam LKPD. Selain itu, LKPD disusun berdasarkan tahapan inkuiri terstruktur. Tahapan model inkuiri terstruktur adalah observasi, hipotesis, koleksi dan organisasi data, dan kesimpulan ${ }^{[12]}$. Tahap observasi dapat mengeksplorasi pengetahuan awal peserta didik. Tahap hipotesis dapat menuntun peserta didik merumuskan pernyataan yang berupa jawaban sementara dari permasalahan yang diberikan. Tahap koleksi dan organisasi data yang terdapat dalam LKPD stoikiometri dapat membimbing peserta didik untuk menemukan konsep melalui pertanyaan yang diberikan. Peserta didik menyimpulkan apa yang telah dipelajari dengan bahasanya sendiri pada kesimpulan.

Komponen kebahasaan LKPD yang dikembangkan memiliki rata-rata momen kappa 0,91 dikategorikan sangat tinggi. Membuktikan LKPD yang disusun sudah menggunakan bahasa komunikatif, dan sesuai dengan kaidah ejaan bahasa Indonesia. Selain itu, pertanyaan-pertanyaan yang diajukan dalam LKPD sudah jelas dan konsisten dalam menggunakan simbol/lambang.

Nilai momen kappa komponen kegrafisan LKPD yang dikembangkan adalah 0,87 dikategorikan sangat tinggi. Membuktikan gambar dan jenis huruf yang terdapat pada LKPD sudah dapat teramati dan dapat dibaca dengan jelas dan LKPD yang dikembangkan telah teratur dari segi tata letak serta pemilihan warna dapat menarik perhatian peserta didik.

Momen kappa dari keempat komponen yang dinilai memiliki rata-rata 0,87 dengan kategori kevalidan sangat tinggi yaitu 0,87. Berdasarkan kategori tersebut maka LKPD stoikiometri dengan tiga level representasi kimia sudah dapat digunakan dalam pembelajaran.

\subsubsection{Revisi}

LKPD stoikiometri berbasis inkuiri terstruktur dengan tiga level representasi diperbaiki sesuai saran yang diberikan oleh validator sebelum diuji coba produk. Setelah LKPD direvisi selanjutnya diserahkan kembali pada validator untuk berdiskusi kembali. Revisi selesai apabila LKPD dinyatakan valid oleh validator. Beberapa komponen LKPD yang disarankan direvisi oleh validator: 1) kegiatan observasi padalangkah kerja 1 telah diperbaiki sesuai indikator pencapaian kompetensi yaitu menjelaskan pengertian mol, 2) memperbaiki peta konsep, 3) memperbaiki ukuran gambar yang disajikan, 4) memperbaiki pernyataan yang kurang tepat pada koleksi dan organisasi data massa molar, 5) memperbaiki cover

\subsubsection{Uji praktikalitas}

Praktikalitas dilakukan terhadap 3 aspek yaitu aspek kemudahan penggunaan, aspek efisiensi waktu, dan aspek manfaat. Data penilaian kepraktisan LKPD dianalisis dengan menggunakan momen kappa. Hasil analisis data praktikalitas LKPD oleh guru dan peserta didik bisa diperhatikan pada Gambar 4.

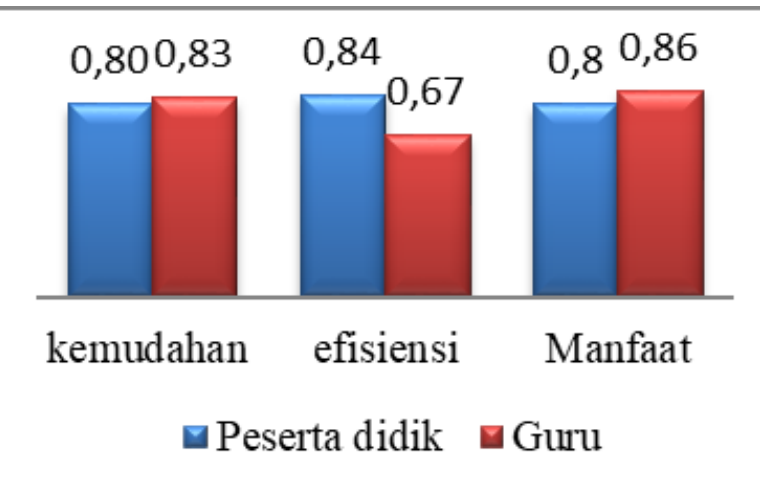

Gambar 4. Hasil analisis data praktikalitas LKPD stoikiometri oleh guru dan peserta didik.

Pada komponen kemudahan penggunaan LKPD memperoleh momen kappa 0,83 oleh guru dan 0,80 oleh peserta didik dikategorikan sangat tinggi. Membuktikan petunjuk penggunaan yang terdapat pada LKPD mudah dipahami. Selain itu, telah menggunakan bahasa yang mudah dimengerti dan komunikatif, serta memiliki ukuran praktis dan mudah dibawa.

Komponen efisiensi waktu pembelajaran diperoleh momen kappa 0,67 oleh guru dikategorikan tinggi dan 0,84 oleh peserta didik dikategorikan sangat tinggi. Membuktikan LKPD stoikiometri yang disusun membantu pembelajaran menjadi efisien. Dari segi manfaat diperoleh momen kappa sebesar 0,86 oleh guru dan 0,80 oleh peserta didik dikategorikan sangat tinggi. Membuktikan LKPD yang disusun bermanfaat untuk guru dan peserta didik dalam melaksanakan pembelajaran seperti pada saat membimbing peserta didik memahami materi. Selain itu, meningkatkan minat belajar peserta didik. Hasil rata-rata uji praktikalitas LKPD stoikiometri oleh 2 orang guru kimia adalah 0,78 dikategorikan tinggi dan dari 29 orang peserta didik 0,81 dikategorikan sangat tinggi. Menandakan LKPD stoikiometri yang dibuat sudah praktis dan dapat digunakan disekolah.

\section{SIMPULAN}

Kesimpulan dari penelitian ini adalah dihasilkan LKPD stoikiometri berbasis inkuiri terstruktur dengan tiga level representasi untuk kelas X SMA. Validitas LKPD yang dihasilkan sangat tinggi yaitu 0,87 dan mempunyai praktikalitas yang tinggi oleh guru yaitu 0,78 dan sangat tinggi oleh peserta didik yaitu 0,81 .

\section{REFERENSI}

1. Brown, T. L., Lemay. R, H. E., Bursten, B. E., Murphy, C. J., \& Woodward, P. M. (2012). Chemistry the Central Science (twelfth edition ed.). Amerika serikat: Pearson Prentice Hall.

2. Assma, S., Fadhilah, R., \& Hadiarti, D. (2018). Pengembangan Modul Pembelajaran Berbasis Multipel Representasi Pada Materi Stoikiometri Kelas X SMA Negeri 01 Rasau Jaya. Ar-Razi Jurnal Ilmiah, 6 (1).

3. Zakiyah, Ibnu, S., \& Subandi. (2018). 
Analisis Dampak Kesulitan Siswa Pada Materi Stoikiometri terhadap Hasil Belajar Termokimia. EduChemia (Jurnal Kimia dan Pendidikan), 3 (1), 119-134.

4. Sunyono, Yuanita, L., \& Ibrahim, M. (2013). Efektivitas Model Pembelajaran Berbasis Multipel Representasi dalam Membangun Model Mental Mahasiswa Topik Stoikiometri. jurnal pendidikan progresif, 3 (1), 65-79.

5. Treagust, D., Chittleborough, G., \& Mamiala, T. (2003). The Role of Submicroscopic and Symbolic Representations in Chemichal Explanations. international journal of science education, 25 (11), 1353-1368.

6. Depdiknas. (2008). Panduan Pengembangan Bahan Ajar.Jakarta: Direktorat Jenderal Manajemen Pendidikan Dasar dan Menengah, Direktorat Pembinaan Sekolah Menengah Atas.

7. Kistiono, Taufik, \& M.Muslim. (2017, September). Desain Lembar Kerja Peserta Didik (LKPD) Ipa Berbasis Saintifik untuk Meningkatkan Pemahaman Konsep di Kelas VII, VII, dan Kelas IX SMP/MTS. Prosiding Seminar Nasional Pendidikan 2017, 704-715.

8. Permatasari, E. A. (2014). Implementasi Pendekatan Saintifik dalam Kurikulum 2013 Pada Pembelajaran Sejarah. ijhe indonesian journal of history education, 3 (1), 11-16.

9. Mizarwan, B., Ratnawulan, \& Gusnedi. (2015). "Pengaruh Lembar Kerja Peserta Didik Berorientasi Inkuiri Terbimbing terhadap Kompetensi IPA Kelas VII SMPN 2 Bukittinggi". Pillar of Physich Education, 6, 41-48.

10. Bunterm, T., Lee, K., Lan Kong, J. N., Srikoon, S., Vangpoomyai, P., Rattanavongsa, I., et al. (2014). Do Different Levels of Inquiry Lead to Different Learning Outcomes? A Comparison between Guided and Structured Inquiry. International Journal of Science Education, 36 (12), 1937-1959.

11. Colburn, A. (2000). "An Inquiry Primer". Sciencescope.

12. Zion, M., \& Mendelovici, R. (2012). Moving from Structured to Open Inquiry: Challenges and Limits. Science Education International, 23 (4), 383-399.

13. Schmid \& Bogner. 2015. Effects of Students' Effort Scores in a Structured Inquiry Unit on Long-Term Recall Abilities of Content Knowledge. Education Research International: Hindawi Publishing Corporation.

14. Sugiarto. (2015). "Peningkatan Hasil Belajar Materi Getaran dan Gelombang Melalui Pembelajaran Inkuiri Terstruktur”. Didaktikum: Jurnal Penelitian Tindakan Kelas, 16 (4).

15. Sugiyono. (2012). Metode Penelitian Pendidikan. Bandung: Alfabeta.

16. Boslaugh, S., \& Watters, P. A. (2008). Statistics in a Nutshell, a Dekstop Quick Referance. United State of America: O'Reiley Media, Inc.

17. Permendikbud.2018. Perubahan Atas Peraturan Menteri Pendidikan dan Kebudayaan No. 24
Tahun 2016 tentang Kompetensi inti dan Kompetensi Dasar Pelajaran Pada Kurikulum 2013 Pada Pendidikan Dasar dan Pendidikan Menengah. Jakarta: Menteri Pendidikan dan Kebudayaan Republik indonesia.

18. Latisma. (2011). Evaluasi Pendidikan. Padang: UNP Press.

19. Sugiyono. 2013. Metode Penelitian Kuantitatif Kualitatif dan R \& D. Bandung: Alfabeta.pada Era Global. 